\title{
Presence of tapeworms (Cestoda) in red fox (Vulpes vulpes) in north-western Poland, with particular emphasis on Echinococcus multilocularis
}

\author{
Agnieszka Tylkowska ${ }^{1}$, Bogumiła Pilarczyk ${ }^{1}$, Renata Pilarczyk ${ }^{2}$, \\ Michał Zyśko ${ }^{3}$, Agnieszka Tomza-Marciniak ${ }^{1}$ \\ ${ }^{1}$ Department of Animal Reproduction Biotechnology and Environmental Hygiene, \\ ${ }^{2}$ Laboratory of Biostatistics, Faculty of Biotechnology and Animal Husbandry, \\ West Pomeranian University of Technology in Szczecin, 71-270 Szczecin, Poland \\ ${ }^{3}$ Biebrza National Park, Osowiec-Twierdza 8, 19-110 Goniądz, Poland \\ Agnieszka.Tomza-Marciniak@zut.edu.pl
}

Received: July 30, 2018

Accepted: February 4, 2019

\begin{abstract}
Introduction: Foxes are a reservoir of parasites that are dangerous to humans. The aim of the study was to determine the parameters associated with the occurrence of tapeworms in red foxes in north-western Poland. Material and Methods: Parasitological sections were taken from 620 red foxes using IST and SCT methods in 18 districts of West Pomerania Province. Results: The extensity of fox infection with tapeworms was $61 \%$. Echinococcus multilocularis, Mesocestoides spp., Dipylidium caninum, and specimens of the genus Taenia were identified. E. multilocularis was found in 11 districts. Mesocestoides spp. demonstrated the highest prevalence $(41.3 \%)$, while E. multilocularis demonstrated the lowest prevalence $(2.9 \%)$; however, it infected foxes with the greatest mean intensity (235.6 tapeworms per fox). The most common co-occurrence in a single host organism was observed for Mesocestoides spp. and tapeworms of the genus Taenia; however, no examples were found of coinfection by E. multilocularis and D. caninum. Conclusion: The occurrence of tapeworms in foxes was high in West Pomerania Province and was often higher than observed in previous years. For this reason, the risk of parasite transmission to humans and domestic animals is mounting. The risk of infection is also amplifying due to the growth of the fox population.
\end{abstract}

Keywords: red fox, Echinococcus multilocularis, Mesocestoides lineatus, Taenia spp., Dipylidium caninum, Poland.

\section{Introduction}

In Poland, a significant increase has been observed in the number of red foxes. According to Polish Hunting Association data, in 1990-2001 their number rose from 56,000 to 148,000 , subsequently rising to over 200,000 in the following years. Currently, the population is estimated at 209,000. Such a rapid increase in the population of red foxes has been attributed to the use of oral rabies vaccines since 1993 in the west of Poland, and throughout the country since 2002. Twice a year, in spring and autumn, lures containing vaccine are distributed by aircraft in fields and forests, and in other non-urban areas inhabited by free-living foxes. This increase in the red fox population has contributed to its expansion into new habitats and, in the course of this expansion, foxes have often entered environments inhabited by people. They have commonly been seen in the vicinity of villages, parks, suburban areas, and within housing estates in large urban agglomerations. Such close contact between fox, man, and man's pets can have negative and potentially fatal consequences for human health.

Foxes are a reservoir of parasites that are dangerous to humans. One of the most dangerous parasites to humans carried by foxes is the tapeworm Echinococcus multilocularis (7). Together with the malaria parasite Plasmodium falciparum, it has been recognised as the most dangerous parasite in the world and is the most dangerous pathogenic parasite occurring in Poland (12).

In humans, tapeworm larvae cause a disease called alveolar echinococcosis (ALV), which is characterised by changes similar to those observed in the course of cancer. The treatment of the disease is long and expensive. Radical surgery is needed to remove the 
lesions, followed by at least a two-year course of antiparasitic chemotherapy. Follow-up examinations are also necessary over the next 10 years. Mortality exceeds $90 \%$ within 10 years of diagnosis in untreated patients; however, surgical treatment and long-term chemotherapy can reduce this figure to $10 \%-14 \%$. Nevertheless, relapses are often observed (15).

Regions endemic for alveolar echinococcosis are found throughout the world. In some provinces of China, more than 400 new cases of disease are diagnosed annually per 100,000 inhabitants. In western Alaska and in the northern part of Siberia, alveolar echinococcosis has been recorded at 98 to 170 cases per 100,000 inhabitants (23). The European registry of alveolar echinococcosis cases estimates the number of diagnosed patients in 1982-2000 to be 559, of whom $42.0 \%$ were in France, $23.6 \%$ in Germany, and 21.1\% in Switzerland (20). However, in 2013 and 2014, 811 and 806 cases of echinococcosis were reported, respectively, with the incidence being around 0.18 per 100,000 inhabitants (12).

Nahorski et al. (24) reported a total of 121 new cases diagnosed between 1990 and 2011. Data from the Polish National Institute of Hygiene indicates diagnosis of alveolar echinococcosis in 109 patients from Poland in the period of 2009 to 2012 , with the presence of two species of tapeworms as the cause: E. multilocularis and E. granulosus. The highest number of alveolar echinococcosis was noted in Warmia-Masuria Province (24), where the highest numbers of infected foxes were found (18).

Mesocestoides tapeworms which live in foxes as final hosts may sporadically appear in humans as random hosts. Humans can be infected by accidental consumption of raw mesentery or blood infected with the larval forms of the tapeworm. A previous study describes 26 cases of human infection by members of the Mesocestoides, of which 18 were associated with Mesocestoides lineatus (14 cases in Japan, 2 in Korea, and 2 in China) (10).

The aim of the present study was to determine the parameters associated with the occurrence of tapeworms in red foxes in north-western Poland.

\section{Material and Methods}

The research was carried out in West Pomerania Province, coastally located in North-Western Poland. The area of the province is over $22,892 \mathrm{~km}^{2}$. Around $35.4 \%$ of its area is covered by forests and nearly $2.9 \%$ by surface waters. The area is typified by a moderate climate with average annual rainfall of 500 to $800 \mathrm{~mm}$, annual temperature of 7 to $9^{\circ} \mathrm{C}$, and significant air humidity due to the close proximity of the sea. The Polish Hunting Association estimates the density of foxes in the area to be 8.5 individuals per 1,000 ha.

The research material consisted of 620 red foxes (Vulpes vulpes) (236 females and 384 males) obtained by reductive shooting in 18 districts of the province. The research on foxes was carried out using security measures recommended by the WHO (1984). The corpses were frozen at $-70^{\circ} \mathrm{C}$ to eliminate the invasiveness of $E$. multilocularis eggs. After four days, parasitological sections of the foxes were taken using sectional methods described by Eckert et al. (6) and by Deplazes and Eckert (4). The intestines were examined using the intestinal scraping technique (IST) and sedimentation and counting technique (SCT). During sectioning, the small intestine was isolated and divided into three sections (duodenum, jejunum, and ileum). Five mucosal smears were taken from different locations in the small intestine and investigated by stereomicroscopy for the presence of intestinal stages of E. multilocularis. Following this, all pieces of the intestine were shaken and washed in water and left to sediment. The sediment was examined in small portions in a Petri dish under a stereomicroscope. The sex of the animals was identified based on the gonads.

The obtained results were analysed using Statistica v. 10.0 software (StatSoft, now Tibco, USA). The Mann-Whitney U-test was used to identify significant differences between the sexes of the foxes with regard to the occurrence of individual tapeworm taxa. In order to determine the significance of differences in the occurrence of tapeworms between individual sections of the gastrointestinal tract and between particular districts of West Pomerania Province, the KruskalWallis test was used.

To describe and characterise the structure of groupings of tapeworms in foxes, the following ecological indicators were used (16):

a) the Janion index $(Z)$ to determine and compare the degree of dominance of parasitophores in foxes by particular tapeworm species. Based on the Janion index, the results were divided into dominant species $(Z>1)$, subdominant species $(0.1<Z<1)$, and satellite species $(Z<0.1)$.

$Z=\frac{A B}{C^{2}}$

where: $\mathrm{A}$ is the number of parasites in the sample; $\mathrm{B}$ is number of infected hosts in the sample; and $\mathrm{C}$ is number of hosts examined.

b) the Jaccard coexistence index $(\mathrm{J})$ to compare the coexistence of particular species of tapeworms, where the feature is the presence of the species in the sample (environment). The value of the indicator will be $100 \%$ in cases when two analysed species of tapeworms are always found to co-occur, regardless of their number, and percentage when these two species are never observed together.

$$
J p 1 p 2=\frac{c}{a+b-c} x 100
$$


where: Jp1p2 is the co-existence index between species $\mathrm{p} 1$ and $\mathrm{p} 2$; $\mathrm{a}$ is the number of occurrences of species $\mathrm{p} 1$; $\mathrm{b}$ is number of occurrences of species $\mathrm{p} 2$; and $\mathrm{c}$ is the number of common occurrences of species $\mathrm{p} 1$ and p2 in the habitat.

Relative density was calculated as the arithmetic mean of the number of individuals of a particular parasite species per host examined.

\section{Results}

The extensity of infection with tapeworms was found to be $61 \%$, while the average infection intensity was 61.4 per fox. The tapeworms E. multilocularis, Mesocestoides spp., Dipylidium caninum, and those of the genus Taenia were identified. The highest prevalence $(41.3 \%)$ and a high mean intensity of infection (71.4 tapeworms per fox) were demonstrated by Mesocestoides spp. E. multilocularis demonstrated the lowest prevalence $(2.9 \%)$ and the greatest mean intensity of infection (235.6 tapeworms per fox) (Table 1).

The dominant species in the cluster was Mesocestoides spp. $(Z=12.2)$. Subdominant species $(0.1<Z<1)$ were found to be Taenia sp. $(Z=0.3)$ and E. multilocularis $(Z=0.2)$. The satellite species $(\mathrm{Z}<0.1)$ emerged as D. caninum $(\mathrm{Z}=0.004)$ (Table 1$)$.

Mesocestoides spp. was the most commonly-found species in both males and females. Although greater extensity of infection was found in males $(43.0 \%)$ than females $(38.6 \%)$, this difference was not statistically significant $(\mathrm{P}>0.05)$. This tapeworm also demonstrated high mean infection intensity, which was higher in females than in males (77.7 parasites in females and 68.0 in males), and this difference was statistically significant (Mann-Whitney U-test, $\mathrm{Z}=2.23 ; \mathrm{P}=0.03$ ). The highest mean intensity of infection was demonstrated by E. multilocularis in both males and females. Greater numbers of this parasite were found in females ( 357.7 organisms) than in males (211.2), although this difference was not statistically significant $(\mathrm{P}>0.05)$ (Table 2).

Table 1. Occurrence of tapeworms in red foxes

\begin{tabular}{|c|c|c|c|c|c|c|c|}
\hline \multirow{2}{*}{ Parasite } & \multirow{2}{*}{$\begin{array}{l}\text { Number of } \\
\text { parasites }\end{array}$} & \multirow{2}{*}{$\begin{array}{l}\text { Number of } \\
\text { infected } \\
\text { foxes/tested } \\
\text { foxes }\end{array}$} & \multirow{2}{*}{$\begin{array}{l}\text { Prevalence } \\
(\%)\end{array}$} & \multicolumn{2}{|c|}{ Intensity of infection } & \multirow{2}{*}{ Relative density } & \multirow{2}{*}{$\begin{array}{l}\text { Janion's Z } \\
\text { indicator }\end{array}$} \\
\hline & & & & Mean & Range & & \\
\hline $\begin{array}{l}\text { Tapeworms } \\
\text { (in total) }\end{array}$ & 23,295 & $378 / 620$ & 61.0 & 61.4 & $1-965$ & 37.5 & 22.9 \\
\hline E. multilocularis & 4,241 & $18 / 620$ & 2.9 & 235.6 & $17-959$ & 6.8 & 0.2 \\
\hline Mesocestoides spp. & 18,356 & $256 / 620$ & 41.3 & 71.4 & $1-650$ & 29.5 & 12.2 \\
\hline Taenia sp. & 624 & $176 / 620$ & 28.4 & 3.6 & $1-13$ & 1.0 & 0.3 \\
\hline D. caninum & 74 & $22 / 620$ & 3.6 & 3.4 & $1-8$ & 0.1 & 0.004 \\
\hline
\end{tabular}

Table 2. Occurrence of tapeworms in red foxes according to sex of host

\begin{tabular}{|c|c|c|c|c|c|c|c|c|c|c|}
\hline \multirow[t]{2}{*}{ Parasite } & \multirow{2}{*}{$\begin{array}{l}\text { Sex of } \\
\text { host } \\
\end{array}$} & \multirow{2}{*}{$\begin{array}{l}\text { Number } \\
\text { of } \\
\text { parasites }\end{array}$} & \multirow{2}{*}{$\begin{array}{l}\text { Number of } \\
\text { infected foxes } \\
\text { /tested foxes }\end{array}$} & \multirow{2}{*}{$\begin{array}{l}\text { Prevalence } \\
(\%)\end{array}$} & \multirow{2}{*}{$\begin{array}{l}\chi^{2} \text { test } \\
\text { score }\end{array}$} & \multicolumn{3}{|c|}{ Intensity of infection } & \multirow{2}{*}{$\begin{array}{l}\text { Relative } \\
\text { density }\end{array}$} & \multirow{2}{*}{$\begin{array}{l}\text { Janion's Z } \\
\text { indicator }\end{array}$} \\
\hline & & & & & & Mean & Range & $\begin{array}{l}\text { Mann-Whitney } \\
\text { test score }\end{array}$ & & \\
\hline \multirow[t]{2}{*}{$\begin{array}{l}\text { Tapeworms } \\
\text { (in total) }\end{array}$} & $\hat{\sigma}$ & 14,783 & $234 / 384$ & 60.9 & \multirow{2}{*}{$\begin{array}{l}\chi^{2}=0.00 \\
P=0.984\end{array}$} & 63.2 & $1-877$ & \multirow{2}{*}{$\begin{array}{l}Z=--0.36 \\
P=0.718\end{array}$} & 38.5 & 23.5 \\
\hline & q & 8,443 & $144 / 236$ & 61.0 & & 58.6 & $1-965$ & & 35.8 & 21.8 \\
\hline \multirow[t]{2}{*}{ E. multilocularis } & $\hat{\sigma}$ & 3,168 & $15 / 384$ & 3.9 & \multirow{2}{*}{$\begin{array}{l}\chi^{2}=3.60 \\
P=0.058\end{array}$} & 211.2 & $17-721$ & \multirow{2}{*}{$\begin{array}{l}Z=-1.90 \\
P=0.058\end{array}$} & 8.3 & 0.3 \\
\hline & q & 1,073 & $3 / 236$ & 1.3 & & 357.7 & $28-959$ & & 4.5 & 0.06 \\
\hline \multirow[t]{2}{*}{$\begin{array}{l}\text { Mesocestoides } \\
\text { spp. }\end{array}$} & $\hat{\sigma}$ & $1,1,216$ & $165 / 384$ & 43.0 & \multirow{2}{*}{$\begin{array}{l}\chi^{2}=1.17 \\
P=0.279\end{array}$} & 68.0 & $1-650$ & \multirow{2}{*}{$\begin{array}{l}Z=2.23^{\mathrm{a}} \\
P=0.03\end{array}$} & 29.2 & 12.6 \\
\hline & q & 7,071 & $91 / 236$ & 38.6 & & 77.7 & $1-396$ & & 30.0 & 11.6 \\
\hline \multirow[t]{2}{*}{ Taenia sp. } & $\hat{\sigma}$ & 366 & $104 / 384$ & 27.1 & \multirow{2}{*}{$\begin{array}{l}\chi^{2}=0.84 \\
P=0.358\end{array}$} & 3.5 & $1-13$ & \multirow{2}{*}{$\begin{array}{l}Z=-1.02 \\
P=0.308\end{array}$} & 1.0 & 0.3 \\
\hline & q & 258 & $72 / 236$ & 30.5 & & 3.6 & $1-11$ & & 1.1 & 0.3 \\
\hline \multirow[t]{2}{*}{$\begin{array}{l}\text { Dipylidium } \\
\text { caninum }\end{array}$} & $\hat{\sigma}$ & 33 & $12 / 384$ & 3.1 & \multirow{2}{*}{$\begin{array}{l}\chi^{2}=0.50 \\
P=0.479\end{array}$} & 2.8 & $1-8$ & \multirow{2}{*}{$\begin{array}{l}Z=-0.76 \\
P=0.448\end{array}$} & 0.09 & 0.003 \\
\hline & q & 41 & $10 / 236$ & 4.2 & & 4.1 & $1-8$ & & 0.2 & 0.007 \\
\hline
\end{tabular}


The presence of tapeworms was identified in all parts of the small intestine: in the duodenum, jejunum, and ileum (Table 3). The general parameters of the occurrence of tapeworms were greater (Kruskal-Wallis test, $\mathrm{H}=288.1 ; \mathrm{P}<0.001)$ in the jejunum than in the duodenum and ileum (Table 3 ).

In the duodenum, Taenia sp. tapeworms were most common (26.5\%); however, the greatest mean intensity of infection was associated with Mesocestoides spp. (4.9 organisms). E. multilocularis was not identified in the duodenum (Table 3) where no dominant species were observed. Mesocestoides spp. $(\mathrm{Z}=0.3)$ and Taenia sp. tapeworms were the subdominant species in this part of the intestine $(\mathrm{Z}=0.1)$, while $D$. caninum was the satellite species $(<0.001)$ (Table 3$)$.

The intensity of infection with Mesocestoides spp., Taenia sp., and Dipylidium caninum, as well as various tapeworms, was significantly greater in the jejunum than in the duodenum or ileum $(\mathrm{P}<0.001)$.

In the jejunum, the greatest prevalence was demonstrated by Mesocestoides spp. (39.4\%). However, the greatest mean intensity of infection was demonstrated by E. multilocularis (99.1 organisms) (Table 3). The dominant species in the jejunum was Mesocestoides spp. $(Z=9.8)$. Taenia sp. tapeworms were classified as subdominant species $(Z=0.1)$, and E. multilocularis $(\mathrm{Z}=0.08)$ and $D$. caninum $(Z=0.003)$ as satellite species (Table 3$)$.

In the ileum, the most commonly identified organism was Mesocestoides spp. (20.8\%). However, the greatest mean intensity of infection in this part of the intestine was demonstrated by E. multilocularis
(136.5 individuals) (Table 3). No dominant species was identified in the ileum. Mesocestoides spp. $(Z=0.8)$ and E. multilocularis $(\mathrm{Z}=0.1)$ were found to be subdominant species, while Taenia sp. $(Z=0.001)$ and D. caninum $(\mathrm{Z}<0.001)$ were seen to be satellite species (Table 3).

Although tapeworms were found in all districts of West Pomerania Province, the occurrence was greater in the south-western part. No statistically significant differences $(\mathrm{P}>0.05)$ were observed between the tested districts with regard to the occurrence of the tapeworms (Fig. 1).

E. multilocularis was found in 11 districts of West Pomerania Province (Fig. 1). The highest prevalence of infection and other associated characteristics were observed in the Myśliborski district, where the tapeworm was observed in four tested foxes. In the Białogardzki district, only one fox was found to be infected. However, this case was characterised by a very high intensity (959 individuals). No statistically significant difference $(\mathrm{P}>0.05)$ was observed between the various districts of the province with regard to the prevalence of $E$. multilocularis.

Our findings indicate that the frequencies of cooccurrence of individual pairs of tapeworms and the strengths of the relationship between them as measured by the Jaccard indicator $(\mathrm{J})$, were different. The most common co-occurrence in a single host organism was observed between Mesocestoides spp. and tapeworms of the genus Taenia sp. (80 co-occurrences, $\mathrm{J}=15.6 \%$ ). No cases of co-occurrence between E. multilocularis and D. caninum were observed (Table 4 ).

Table 3. Occurrence of tapeworms in red foxes according to their location in the small intestine

\begin{tabular}{|c|c|c|c|c|c|c|c|c|c|c|}
\hline \multirow[b]{2}{*}{ Parasite } & \multirow{2}{*}{$\begin{array}{l}\text { Part of the } \\
\text { small } \\
\text { intestine }\end{array}$} & \multirow{2}{*}{$\begin{array}{l}\text { Number } \\
\text { of } \\
\text { parasites }\end{array}$} & \multirow{2}{*}{$\begin{array}{l}\text { Number of } \\
\text { infected } \\
\text { foxes /tested } \\
\text { foxes }\end{array}$} & \multirow[b]{2}{*}{$\begin{array}{l}\text { Prevalence } \\
(\%)\end{array}$} & \multirow[b]{2}{*}{$\begin{array}{l}\text { Cochran } \\
\text { test score }\end{array}$} & \multicolumn{3}{|c|}{ Intensity of infection } & \multirow[b]{2}{*}{$\begin{array}{l}\text { Relative } \\
\text { density }\end{array}$} & \multirow[b]{2}{*}{$\begin{array}{l}\text { Janion's Z } \\
\text { indicator }\end{array}$} \\
\hline & & & & & & Mean & Range & $\begin{array}{l}\text { Kruskal-Wallis } \\
\text { test score }\end{array}$ & & \\
\hline \multirow{3}{*}{$\begin{array}{l}\text { Tapeworms } \\
\text { (in total) }\end{array}$} & Duodenum & 931 & $288 / 620$ & 46.4 & \multirow{3}{*}{$\begin{array}{l}Q=195.2 \\
P<0.001\end{array}$} & $2.9^{\mathrm{A}}$ & $1-97$ & \multirow{3}{*}{$\begin{array}{l}H=147.5 \\
P<0.001\end{array}$} & 1.5 & 0.7 \\
\hline & Jejunum & 17,624 & $338 / 620$ & 54.5 & & $44.1^{\mathrm{B}}$ & $1-676$ & & 28.4 & 15.5 \\
\hline & Ileum & 4,740 & $160 / 620$ & 25.8 & & $28.6^{\mathrm{A}}$ & $1-535$ & & 7.7 & 2.0 \\
\hline \multirow{3}{*}{ E. multilocularis } & Duodenum & 0 & $0 / 620$ & - & \multirow{3}{*}{$\begin{array}{l}\mathrm{Q}=36.0 \\
\mathrm{P}<0.001\end{array}$} & 0 & 0 & \multirow{3}{*}{$\begin{array}{l}H=0.530 \\
P=0.467\end{array}$} & & \\
\hline & Jejunum & 1,784 & $18 / 620$ & 2.9 & & 99.1 & $2-425$ & & 2.9 & 0.08 \\
\hline & Ileum & 2,457 & $18 / 620$ & 2.9 & & 136.5 & $2-534$ & & 4.0 & 0.1 \\
\hline \multirow{3}{*}{$\begin{array}{l}\text { Mesocestoides } \\
\text { spp. }\end{array}$} & Duodenum & 685 & $141 / 620$ & 22.7 & \multirow{3}{*}{$\begin{array}{l}Q=129.6 \\
P<0.001\end{array}$} & $4.9^{\mathrm{A}}$ & $1-96$ & \multirow{3}{*}{$\begin{array}{l}H=183.2 \\
P<0.001\end{array}$} & 1.1 & 0.3 \\
\hline & Jejunum & 15,418 & $244 / 620$ & 39.4 & & $63.2^{\mathrm{B}}$ & $1-579$ & & 24.9 & 9.8 \\
\hline & Ileum & 2,253 & $129 / 620$ & 20.8 & & $17.5^{\mathrm{A}}$ & $1-196$ & & 3.6 & 0.8 \\
\hline \multirow{3}{*}{ Taenia sp. } & Duodenum & 234 & $164 / 620$ & 26.5 & \multirow{3}{*}{$\begin{array}{l}Q=205.6 \\
P<0.001\end{array}$} & $1.4^{\mathrm{A}}$ & $1-5$ & \multirow{3}{*}{$\begin{array}{l}H=71.4 \\
P<0.001\end{array}$} & 0.4 & 0.1 \\
\hline & Jejunum & 363 & $119 / 620$ & 19.2 & & $3.1^{\mathrm{B}}$ & $1-10$ & & 0.6 & 0.1 \\
\hline & Ileum & 27 & $16 / 620$ & 2.6 & & $1.7^{\mathrm{A}}$ & $1-3$ & & 0.04 & 0.001 \\
\hline \multirow{3}{*}{$\begin{array}{l}\text { Dipylidium } \\
\text { caninum }\end{array}$} & Duodenum & 12 & $12 / 620$ & 1.9 & \multirow{3}{*}{$\begin{array}{l}Q=19.4 \\
P<0.001\end{array}$} & $1.0^{\mathrm{A}}$ & 1 & \multirow{3}{*}{$\begin{array}{l}H=16.7 \\
P<0.001\end{array}$} & 0.02 & 0.0004 \\
\hline & Jejunum & 59 & $19 / 620$ & 3.1 & & $3.1^{\mathrm{B}}$ & $1-8$ & & 0.1 & 0.003 \\
\hline & Ileum & 3 & $3 / 620$ & 0.5 & & $1.0^{\mathrm{A}}$ & 1 & & 0.005 & 0.00002 \\
\hline
\end{tabular}

Different capital letters indicate statistically significant differences at $\mathrm{P} \leq 0.01$ 

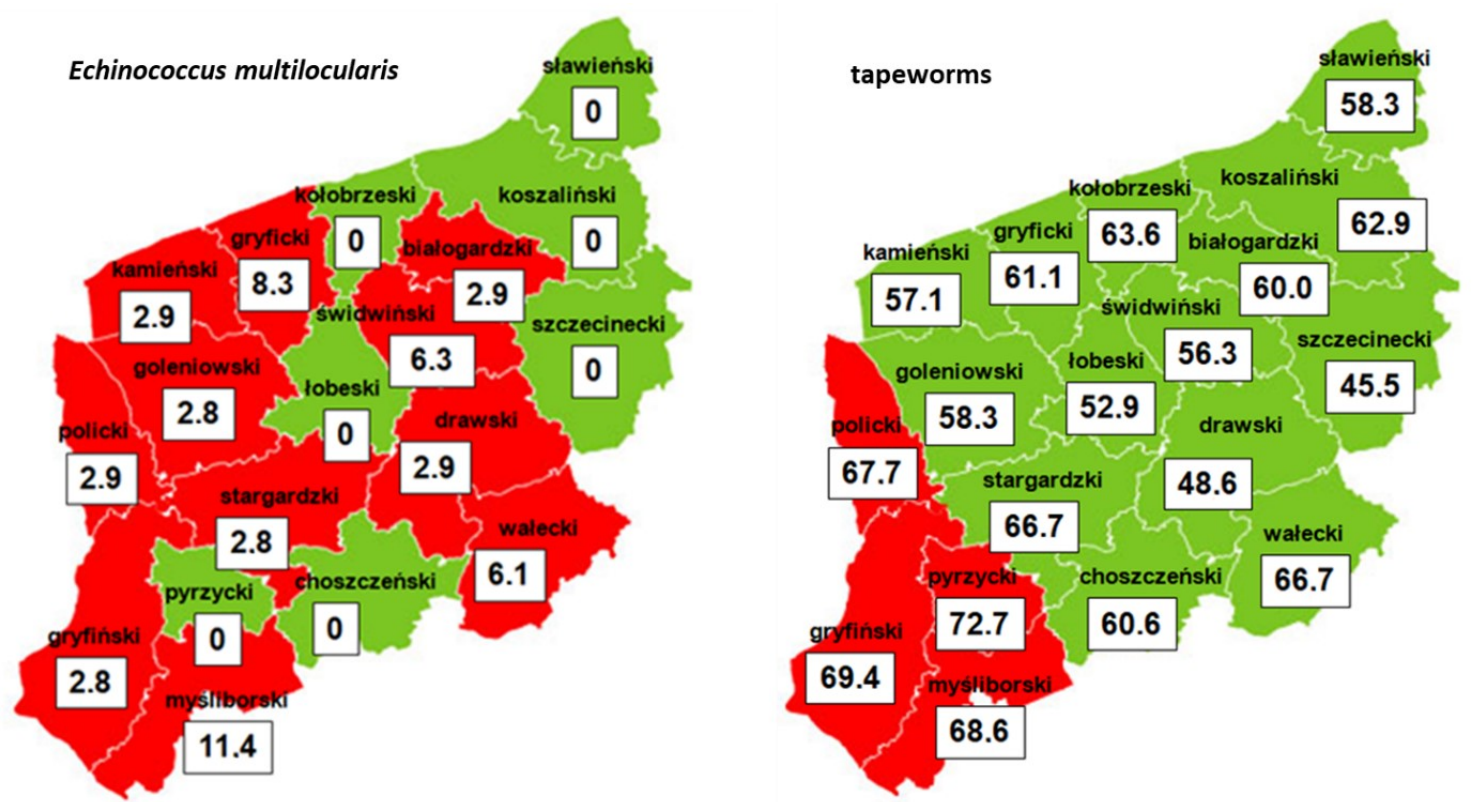

Fig. 1. Extensity of tapeworms and Echinococcus multilocularis infection (\%) of red foxes in particular districts of West Pomerania Province; figures marked in red indicate the greatest extensity

Table 4. The frequency of co-occurrence of particular types of tapeworm in a single host organism

\begin{tabular}{lllll}
\hline Parasite & $\begin{array}{l}\text { Echinococcus } \\
\text { multilocularis }\end{array}$ & $\begin{array}{l}\text { Mesocestoides } \\
\text { lineatus }\end{array}$ & Taenia sp. & $\begin{array}{l}\text { Dipylidium } \\
\text { caninum }\end{array}$ \\
\hline Echinococcus multilocularis & $\mathbf{1 8}$ & 3.4 & 2.5 & $\begin{array}{l}\text { Not } \\
\text { identified }\end{array}$ \\
\hline Mesocestoides spp. & $\begin{array}{l}9 \\
(1.5)\end{array}$ & $\mathbf{2 5 6}$ & 15.6 & 0.7 \\
\hline Taenia sp. & $\begin{array}{l}5 \\
(0.8)\end{array}$ & $\begin{array}{l}80 \\
(12.9)\end{array}$ & $\mathbf{1 7 6}$ & 1.0 \\
\hline Dipylidium caninum & Not identified & $\begin{array}{l}2 \\
(0.3)\end{array}$ & $\begin{array}{l}2 \\
(0.3)\end{array}$ & $\mathbf{2 2}$ \\
\hline
\end{tabular}

Bold text - the number of foxes in which a tapeworm species was found; dark grey field - the number of cooccurring tapeworm species (prevalence); light grey field - the Jaccard coexistence index between the species of tapeworms (\%)

\section{Discussion}

Extensity and intensity of tapeworm infection. Mesocestoides spp. is the most widespread parasite of foxes, both in Poland and other European countries. Karamon et al. (18) found Mesocestoides spp. to be the most prevalent parasites in red foxes in Poland, with a mean prevalence of $84.1 \%$. Large extensities of the infection with Mesocestoides spp. have been also found in Lithuania (78\%) (2) and in Iran (81.8\%) (4). However, a few countries have reported the presence of Mesocestoides spp. in small numbers of foxes, including the Netherlands (5.9\%) (11) and Denmark (Southern Jutland - 8.3\%) (1). In this study, Mesocestoides spp. demonstrated by far the greatest incidence. Mesocestoides spp. was also characterised by a high intensity of infection in foxes. Our results are higher than those reported by Karamon et al. (18) for red foxes from other regions of Poland (112.9 individuals). A much greater intensity of infection was found by Shimalov and Shimalov (27) in foxes in Belarus, ranging from 1 to 1,400 individuals.
The high occurrence of Mesocestoides spp. observed in foxes is related to the development of the tapeworm cycle in which two groups of intermediate hosts exist: the first being the moss mites of the Oribatoidea family, and the second being minor vertebrates (amphibians, reptiles, birds, and mammals) which are the basic fox diet (26).

As mentioned above, for safety reasons, the fox carcasses were stored at $-70^{\circ} \mathrm{C}$. However, the consequent low temperature freezing, thawing, and autolysis results in significant damage to Taenia, which prevented these tapeworms from being identified to the species level; hence, they were classified simply as Taenia sp. In Europe, the following species of Taenia were most commonly identified in foxes: Taenia crassiceps $(17.5 \%$ in Italy and $22.1 \%$ in the Netherlands) $(8,11)$, Taenia pisiformis $(12.8 \%$ in Belarus and $5.3 \%$ in Italy) $(8,28)$, and Taenia polyacantha (61.7\% in Lithuania) (2). The frequency of infection of foxes by these tapeworm species is associated with the availability of rodents and other small mammals, which are indirect hosts for these 
parasites. The extensity of $D$. caninum infection in foxes observed in the present study was lower than observed by Pacoń et al. (26) in Lower Silesia Province (7.1\%).

E. multilocularis has only been observed in the northern hemisphere. In Europe until 1990, E. multilocularis was endemic in eastern France, southern Germany, Switzerland, and Western Austria (7). However, in the period of 1990-2000, its range expanded into Belgium, Lichtenstein, Luxembourg, Poland, the Czech Republic, the Netherlands, Slovakia, and Denmark. In Poland, E. multilocularis was identified for the first time in two foxes from the Gdańsk area in 1994 (22). In the following years, it was observed almost throughout the entire country. The focal occurrence of E. multilocularis in foxes poses a high risk of infection for humans, as most of the outbreaks are located in regions which are densely populated and attractive to tourists.

The extensity of infection of foxes by E. multilocularis recorded in the present study was low. In other regions of Poland, the extensity of E. multilocularis infection in foxes was found to increase generally over time: from $6.5 \%$ to $42.7 \%$ in Podlasie Province and from $0.6 \%$ to $39.3 \%$ in Subcarpathia Province $(14,18)$.

This extensity also varies across the continent of Europe. While E. multilocularis is most commonly noted in Germany, France, Switzerland, and Lithuania, it is less commonly observed in other countries, such as Ireland, Sweden, and Finland (25).

In the present study, E. multilocularis demonstrated the highest mean intensity of infection among the identified tapeworms (17 to 959 individuals per fox). Echoing the case of Mesocestoides spp., these values were lower than those obtained by Karamon et al. (18) for other parts of Poland (mean infection intensity of 4,473.8, range 1-260,000) and by Shimalov and Shimalov (28) in Belarus (1 to 5,000 individuals).

It was observed that a high intensity of E. multilocularis infection in foxes does not significantly weaken their condition, as the small tapeworms living between the intestinal villi are virtually non-pathogenic for final host. However, high levels of contamination have a considerable influence on their spread through the environment by both final and intermediate hosts. The parasites are located in the small intestine of final hosts, these being members of the Canidae, order Carnivora: red foxes (Vulpes vulpes), polar foxes (Alopex lagopus), steppe foxes (Vulpes corsac), Tibetan foxes (Vulpes ferrilata), raccoon dogs (Nyctereutes procyonoides), wolves (Canis lupus), and coyotes (Canis latrans). This parasite is also found in dogs and to a lesser extent in cats, especially in endemic areas. Many of the intermediate hosts of E. multilocularis are small rodents, such as the field vole (Microtus arvalis), red vole (Clethrionomys glareolus), European water vole (Arvicola terrestris), muskrat (Ondatra zibethicus), forest mouse (Apodemus flavicollis), house mouse (Mus musculus), field mouse (Apodemus agrarius), European pine vole (Pitymus subterraneus), and coypu (Myocastor coypus), as well as the members of the mole family (Talpidae), the shrew family (Soricidae), the pika family (Ochotonidae), and the leporids (Leporidae). Pigs, wild boars, horses, monkeys, and humans may also be intermediate carriers (7).

The appearance of foxes infected with E. multilocularis close to human habitation has been associated with an alarming increase in parasite infection among domestic animals living close to humans, mostly cats and dogs. Dogs become infected with E. multilocularis by eating intermediate hosts living in urban areas, in gardens, or in city parks (23). This can present a threat to humans when dogs have unlimited access to forest areas, meadows, and fields; they can hunt for small mammals and then return to human settlements. However, infected dogs and cats are less likely to transmit this tapeworm to humans.

In Poland, the occurrence of E. multilocularis in dogs was found for the first time in Subcarpathia Province, where it is believed to be endemic (17). In Switzerland and Germany, the eggs have been found in the faeces of dogs with prevalence of $7.0 \%$ and $0.35 \%$, respectively, and cats (prevalence of $3.0 \%$ and $0.29 \%$, respectively) (5).

In this study, no significant differences in the infection were observed between males and females, which corresponds to the results of other authors. This is probably due to the fact that both males and females live in the same habitat and consume similar diets: one based on rodents, which are intermediate hosts of many tapeworm species. Eating this kind of prey can contribute to the high levels of tapeworm infection seen in both sexes.

The location of various species of tapeworm in the intestine. The present findings show that Mesocestoides spp. favours the jejunum as its living environment, as opposed to tapeworms of the genus Taenia, which prefer the duodenum. The low prevalence of $D$. caninum in foxes does not allow a precise estimation to be made of its preferred location. However, existing data suggest a preference for the duodenum and jejunum. Unfortunately, the body of literature is too small to allow a more precise determination and refers only to the topical structure of E. multilocularis. Therefore, further research is necessary.

Tackmann et al. (28) noted that the preferred location of mature individuals of E. multilocularis is the lower part of the small intestine. Our present findings correspond with those of previous studies, which demonstrated that $E$. multilocularis was found in the jejunum and ileum. The presence of this parasite in the duodenum has not been observed. Karamon et al. (19) report that the parasite was more likely to be found in the lower and middle parts of the intestine than in the upper part. 
In all foxes examined in the present study, E. multilocularis was found at similar levels in the jejunum and ileum. However, Karamon et al. (19) found it to be present in all three parts of the small intestine in 15 foxes, in five in the middle and lower parts, only in one in the lower part, and only in one in the middle part. None of the foxes was found to possess the tapeworm only in the upper part.

In the jejunum, a lower mean intensity of infection and a narrower range of infection intensity were found compared to the ileum. Similarly, Karamon et al. (19) reported lower intensity of infection in the upper and middle parts of the intestine than in the lower part. Also Umhang et al. (29) found preferential localisation of E. multilocularis in the posterior part of the intestine of definitive hosts ( $>40 \%$ of the parasite burden). Karamon et al. (18) proposed that since the mature form of E. multilocularis is observed more frequently in foxes in the lower parts of the small intestine, the upper part is not necessary for diagnostic testing. This will doubtless result in easier and less time-consuming testing procedures.

The regional variation in the occurrence of infected foxes. Tapeworms are most commonly found in the south-western part of the West Pomeranian Province. The occurrence of E. multilocularis deserves special attention. Studies on its prevalence in foxes give an indication of its endemic occurrence in various areas of Poland and Europe (18). Our present findings indicate it to be present in 11 districts within the West Pomeranian Province. No areas in the province were found to be endemic for the parasite.

Large proportions of foxes infected with E. multilocularis have been found in various locations in Poland, including the Olecko-Gołdap (62.9\%), Kętrzyn (55.9\%), and Nidzica (53.8\%) districts of Warmia-Masuria Province (39.6\%); and in the Janów Lubelski (44.4\%) and Parczew (36.4\%) districts of Lublin Province (18.2\%) (18). Therefore, these areas were considered endemic for the occurrence of E. multilocularis in Poland.

Our findings confirm the most common cooccurrence to be of Mesocestoides spp. and Taenia sp. Similarly, Pacoń et al. (24) and Rajkovic-Janje et al. (25) also noted a higher frequency of co-occurrence between those parasites.

In summary, the parameters of tapeworm occurrence in foxes in West Pomeranian Province reached high values, often higher than those found in earlier years in the studied area. This phenomenon certainly predisposes humans and domestic animals to an increased risk of parasite transmission, which can threaten their health or even their lives. The risk of infection increases also due to a burgeoning fox population many members of which must seek new territories and encroach upon areas of human settlement.
Conflict of Interests Statement: The authors declare that there is no conflict of interests regarding the publication of this article.

Financial Disclosure Statement: The source of funding of research and the article was University funds.

Animal Rights Statement: None required.

\section{References}

1. Al-Sabi M.N.S., Halasa T., Kape C.M.O.: Infections with cardiopulmonary and intestinal helminths and sarcoptic mange in red foxes from two different localities in Denmark. Acta Parasitol 2014, 59, 98-107.

2. Deplazes P., Eckert J.: Diagnosis of the Echinococcus multilocularis infection in final hosts. Appl Parasitol 1996, 37, 245-252.

3. Bružinskaite-Schmidhalter R., Sarkunas M., Malakauskas A., Mathis A., Torgerson P.R., Deplazes P.: Helminths of red foxes (Vulpes vulpes) and raccoon dogs (Nyctereutes procyonoides) in Lithuania. Parasitol 2012, 139, 120-127.

4. Dalimi A., Sattari A., Motamedi G.: A study on intestinal helminthes of dogs, foxes, and jackals in the western part of Iran. Vet Parasitol 2006, 142, 129-133.

5. Dyachenko V., Pantchev N., Gawlowska S., Vrhovec M.G., Bauer C.: Echinococcus multilocularis infections in domestic dogs and cats from Germany and other European countries. Vet Parasitol 2008, 157, 244-253.

6. Eckert J., Deplazes P., Ewald D., Gottstein B.: Parasitologische und immunologische Methoden zum Nachweis von Echinococcus multilocularis bei Füchsen. Mitt Österr Ges Tropenmed Parasitol 1991, 13, 25-30.

7. Eckert J., Gemmell M.A., Meslin F.X., Pawłowski Z.S.: WHO/OIE manual on echinococcosis in humans and animals: a public health problem of global concern. WHO/WOAH Ed. Paris (OIE), 2001, bpp. 1-265.

8. Fiocchi A., Gustinelli A., Gelmini L., Renzi M., Fontana M.C., Poglayen G.: Helminth parasites of the red fox Vulpes vulpes (L., 1758) and the wolf Canis lupus italicus Altobello, 1921 in Emilia-Romagna, Italy. Ital J Zool 2016, 83, 4, 503-513.

9. Fischer C., Reperant L., Weber J.M., Ochs H., Deplazes P.: Relation in the presence of various parasites in the red fox (Vulpes vulpes) in Geneva. Swiss Med Wkly 2003, 133, 61.

10. Fuentes M.V., Galan-Puchades M.T., Malone J.B.: Short report: a new case report of human Mesocestoides infection in the United States. Am J Trop Med Hyg 2003, 68, 566-567.

11. Franssen F., Nijsse R., Mulder J., Cremers H., Dam C., Takumi K., van der Giessen J.: Increase in number of helminth species from Dutch red foxes over a 35-year period. Parasit Vectors 2014, 7, 166.

12. Gawor J.: Alveolar echinococcosis in Europe and Poland threats to humans. Przegl Epidemiol 2016, 70, 281-288.

13. Gawor J., Malczewski A.: The tapeworm in foxes as a cause of a dangerous zoonosis alveolar echinococcosis in Poland. Kosmos 2005, 54, 89-94.

14. Gawor J., Malczewski A., Rocki B., Malczewska M., Borecka A.: Prevalence of the dangerous for humans tapeworm Echinococcus multilocularis in red foxes in Poland. Med Weter 2004, 60, 489-491.

15. Grzeszczuk A., Łapiński T.W., Prokopowicz D.: Clinical and epidemiological aspects of alveolar echinococcosis. Med Weter 2001, 57, 21-23.

16. Janion S.M.: Certain host-parasite relationship between rodents (Muridae) and fleas (Aphaniptera). Ekol Pol 1968, 16, 461-506. 
17. Karamon J., Samorek-Pierog M., Kochanowski M., Dabrowska J., Sroka J., Golab E., Umhang G., Cencek T.: First detection of Echinococcus multilocularis in dogs in a highly endemic area of Poland. Folia Parasitol (Praha) 2016, 63, 018.

18. Karamon J., Dąbrowska J., Kochanowski M., SamorekPieróg M., Sroka J., Różycki M., Bilska-Zając E., Zdybel J., Cencek T.: Prevalence of intestinal helminths of red foxes (Vulpes vulpes) in central Europe (Poland): a significant zoonotic threat. Parasit Vectors 2018, 11, 436.

19. Karamon J., Sroka J., Cencek T., Michalski M.M., Zięba P., Karwacki J.: Prevalence of Echinococcus multilocularis in red foxes in two eastern provinces of Poland. Bull Vet Inst Pulawy 2011, 55, 429-433.

20. Karamon J., Ziomko I., Cencik T., Sroka J., Zięba P.: Prevalence of Echinococcus multilocularis in red foxes in the Lublin voivodeship, Poland: preliminary study. Med Weter 2008, 64, 1237-1239.

21. Kern P., Bardonnet K., Renner E., Auer H., Pawłowski Z., Ammann R.W., Vuitton D.A., Kern P.: European Echinococcosis Registry: human alveolar echinococcosis, Europe, 1982-2000. Emerg Infect Dis 2003, 9, 343-349.

22. Malczewski A., Rocki B., Ramisz A., Eckert J.: Echinococcus multilocularis (Cestoda), the causative agent of alveolar echinococcosis in humans: first record in Poland. J Parasit 1995, 81, 318-321.

23. Moro P., Schantz P.M.: Echinococcosis: a review. Int J Infect Dis 2009, 13, 125-133.

24. Nahorski W.L., Knap J.P., Pawłowski Z.S., Krawczyk M., Polański J., Stefaniak J., Patkowski W., Szostakowska B., Pietkiewicz H., Grzeszczuk A., Felczak-Korzybska I., Gołąb E.,
Wnukowska N., Paul M., Kacprzak E., SokolewiczBobrowska E., Niścigorska-Olsen J., Czyrznikowska A., Chomicz L., Cielecka D., Myja P.: Human alveolar echinococcosis in Poland: 1990-2011. PLoS Negl Trop Dis 2013, 7, 1, e1986.

25. Oksanen A., Siles-Lucas M., Karamon J., Possenti A., Conraths F., Romig T., Wysocki P., Mannocci A., Mipatrini D., La Torre G., Boufana B., Casulli A.: The geographical distribution and prevalence of Echinococcus multilocularis in animals in the European Union and adjacent countries: A systematic review and meta-analysis. Parasit Vectors 2016, 9, 519.

26. Pacoń J., Sołtysiak Z., Nicpoń J., Janczak M.: Prevalence of internal helminths in red foxes (Vulpes vulpes) in selected regions of Lower Silesia. Med Weter 2006, 62, 67-69.

27. Rajkovic-Janje R., Marinculic A., Bosnic S., Benic M., Vinkovic B., Mihaljevic Z.: Prevalence and seasonal distribution of helminth parasites in red foxes (Vulpes vulpes) from the Zagreb County (Croatia). Z Jagdwiss 2002, 48, 151-160.

28. Shimalov V.V., Shimalov V.T.: Helminth fauna of the red fox (Vulpes vulpes Linnaeus, 1758) in southern Belarus. Parasitol Res 2003, 89, 77-78.

29. Tackmann K., Mattis R., Conraths J.: Detection of Echinococcus multilocularis in foxes: evaluation of a protocol of the intestinal scraping technique. J Vet Med B Infect Dis Vet Public Health 2006, 53, 395-398.

30. Umhang G., Woronoff-Rhenb N., Combes B., Boué F.: Segmental sedimentation and counting technique (SSCT): An adaptable method for qualitative diagnosis of Echinococcus multilocularis in fox intestines. Exp Parasitol 2011, 128, 57-60. 